\title{
os estrangeiros de azul corvo, de adriana lisboa
}

\section{The foreigners of Azul corvo, by Adriana Lisboa}

\section{Allysson Casais ${ }^{1}$}

Resumo: Este trabalho tem o propósito de entender como o romance Azul corvo (2010), de Adriana Lisboa, representa as diferentes maneiras de ser estrangeiro no mundo atual e os processos identitários e afetivos envolvidos na experiência. A obra narra a história de Vanja, uma adolescente de 13 anos que, após a morte da mãe, se muda do Brasil para os Estados Unidos, país onde nasceu, na busca por seu pai biológico. Em terras norte-americanas, a protagonista passa por transformações e se depara com outros imigrantes latinos vivendo experiências de errâncias que diferem da sua. Com base nas teorias de Augé (1995), Said (2003), Santiago (2008), Canclini (2014), entre outros, chegamos à conclusão de que Lisboa cria uma obra em que as modificações do espaço no qual a narradora se encontra inserida ao longo da narrativa são um reflexo de mudanças identitárias pelas quais ela passa, e que dizem respeito ao deslocamento transnacional de pessoas, o qual se dá de maneira diferente com base nos documentos carregados por esses indivíduos.

Palavras-chaves: Imigração; Deslocamento; Adriana Lisboa; Azul corvo.

Abstract: This paper aims at understanding how the novel, Azul corvo (2010), by Adriana Lisboa, represents the different ways of being a foreigner in today's world and the identity and emotional processes that are involved in such experience. The book tells the story of Vanja, a thirteen-year-old teenager that, after her mother's death, moves from Brazil to the United States, her country of birth, in search of her biological father. In northern lands, the protagonist undergoes transformations and comes across other latino immigrants living displacement experiences different from her own. Based on the theories of Augé (1995), Said (2003), Santiago (2008), Canclini (2014), among others, we came to the conclusion that the changes in the space in which the narrator is in are a reflection of the identity shifts that the protagonist has, and, in regards to transnational migration, that it happens differently based on the documentation the individual carries.

Keywords: Immigration; Displacement; Adriana Lisboa; Azul corvo.

1 Mestre em Estudos Literários pela Universidade Federal Fluminense (UFF). Email: allyssoncasais@ id.uff.br 
ROMA (2018), filme de Alfonso Cuarón, abre com água. Água e sabão. Ela surge na tela e se retira, antes de reaparecer em um movimento que imita as ondas do mar vistas por cima. O som de uma vassoura sendo esfregada no chão e de água indo ralo abaixo nos informa que estamos perante uma cena de faxina. Em contraste, um trecho sobre limpeza em Azul corvo (2010), romance de Adriana Lisboa, é marcado por sua secura. Vanja, a protagonista, recentemente chegada aos Estados Unidos (EUA), limpa as janelas de sua nova casa em Colorado com um papel úmido. Umidade causada não por água, mas, apesar de a narrativa não revelar de maneira explícita, provavelmente por um dos sprays de limpeza usados popularmente nos EUA.

Um dos primeiros sinais de assimilação de Vanja a sua nova cultura, dessa forma, se dá neste curto parágrafo que pode passar despercebido no quarto capítulo do livro. O jogar água, marco da higienização latina, mais especificamente, para o nosso caso, da brasileira, é deixado de lado por uma economia norte-americana: o papel toalha e o spray. A passagem, portanto, é um exemplo daquilo que visamos analisar em nossa leitura do romance de Lisboa. Acreditamos que a narrativa - história de uma adolescente de treze anos que, após a perda da mãe, se muda para os EUA em busca de seu pai estadunidense - tem como um de seus eixos principais o contraste entre duas Américas - a latina, fadada a ocupar a periferia global, e a anglófona, núcleo do chamado primeiro mundo - e, consequentemente, aborda questões identitárias e afetivas daqueles indivíduos que transitam entre esses dois espaços.

O deslocamento é tema recorrente na literatura de Adriana Lisboa. Em entrevista concedida à revista Belas Infiéis, a autora afirma que "a errância, o deslocamento, a migração a expatriação são fenômenos que me interessam, porque penso que deixam mais visível o caráter essencialmente passageiro de nossas próprias vidas" (LISBOA, 2013, p. 214). Desse modo, Azul corvo, acompanhado por outros romances como Hanói (2013) e Rakusisha (2015), faz parte de um grupo de obras de Lisboa que tem a questão da migração em seu cerne. Ao lançarmos um olhar para a produção da autora, por conseguinte, torna-se claro seu pertencimento a um conjunto de escritores no Brasil contemporâneo cujas obras abordam questões ligadas à migração. 
Para Maria Isabel Edom Pires (2014), a encarnação do migrante contemporâneo nasce do mesmo lugar que o intelectual entre dois mundos de Edward Said: da oposição ao princípio de confinamento do Estado moderno, que resulta no exílio, no desabrigo e na ruína do imperialismo. Logo, segundo a crítica, um dos modos de ler a literatura brasileira contemporânea é pensando a locomoção de autores e personagens. Entretanto, há uma distinção entre o tema na literatura atual em contraste à tradição. Escreve a autora:

Ao mundo racional, ordenado do viajante-naturalista, ao doce mundo das viagens do personagem jovem e mundano do século XIX, ao mundo sacrificado e laboral do imigrante do início do século $X X$, contrapõe-se a figura contemporânea do viajante fora das regras, libertário e muitas vezes anônimo da literatura brasileira contemporânea (PIRES, 2014, p. 391).

Edom Pires, assim, identifica em seu ensaio três momentos de viagem na tradição cultural brasileira. No primeiro, o viajante-naturalista vinha ao "Novo Mundo" com o intuito de catalogá-lo para ampliar o conhecimento científico europeu sobre o território brasileiro. Podemos citar, por exemplo, o príncipe Maximiliano de Wied-Neuwied, cuja vinda aos trópicos entre 1815 e 1817 resultou no livro Viagem ao Brasil. Já no segundo caso, a viagem seguia caminho oposto - era aquele nascido no espaço da antiga colônia que se deslocava para o "Velho Mundo". Edom Pires explica que, no século XIX, o jovem brasileiro viajava à Europa para seus estudos e voltava com o objetivo de construir um novo Brasil seguindo os padrões europeus. Observamos aqui que esse segundo momento constatado pela crítica condiz com a "Linhagem de Nabuco" assinalada por Claudete Daflon (2002) em sua tese, na qual a pesquisadora observa como há uma vertente de viagem na literatura brasileira em que se inferioriza o Brasil perante a antiga metrópole. Em vista disso, com base no estudo de Daflon, pode-se adicionar uma outra circunstância ao segundo momento não considerada por Edom Pires: a "Linhagem modernista", em que o intelectual brasileiro viajava para o continente europeu sem rebaixar sua pátria. Por fim, o terceiro momento identificado por Edom Pires se refere ao imigrante do século XX que chega ao Brasil nos navios de grande porte. A pesquisadora cita a literatura de Nélida Piñon, José Clemente Pozenato e Milton Hatoum como exemplos de narrativas sobre esse período, mas neste artigo não podemos deixar de 
mencionar também Samuel Rawet, que, na década de 50, se torna o primeiro escritor em nossa literatura a colocar a experiência do imigrante no núcleo de suas obras.

Considerando estes três momentos de viagem em nossa cultura, a literatura brasileira contemporânea, para Edom Pires, marca uma quarta e nova forma de migração brasileira que varia entre a "consciência do exílio" e o "contato com a clandestinidade" (PIRES, 2014, p. 392). Segundo a pesquisadora, é na gradação entre esses dois pontos que Azul corvo se encontra. Voltaremos mais à frente à análise de Edom Pires do romance de Lisboa, mas por agora, basta afirmar que a narrativa faz parte desse novo momento na literatura brasileira e que, em nossa leitura, há quatro pontos essenciais para entender como o tema de deslocamento é trabalhado em Azul corvo: (1) o contraste entre Brasil e EUA; (2) a mudança identitária dos personagens; (3) a experiência clandestina; e, (4) a formação de família para além de laços sanguíneos.

\section{brasil/eua: primos distantes}

"A carta seria postada no Brasil," narra Vanja ao ir ao correio enviar uma correspondência a Fernando, ex-esposo de sua falecida mãe que a menina esperava que a acolhesse nos Estados Unidos enquanto ela procurava por seu pai biológico, "distante primo americano do sul que tão pouco em comum tinha com o primo americano do norte" (LISBOA, 2010, p. 58).

Brasil e EUA, sendo assim, são para Vanja como parentes distantes. A analogia, para além da questão histórica de ambas as nações serem territórios americanos colonizados por poderes europeus, remete também à biografia da personagem, dividida entre os dois países. Nascida no Novo México, sudoeste dos EUA, Vanja se muda com sua mãe, Suzana, brasileira que imigrara para o Texas em sua adolescência, de Albuquerque para Copacabana antes de completar dois anos de idade. Desse modo, sua história pessoal está suturada por fios que unem Brasil e Estados Unidos. Esses fios, porém, estão frouxos uma vez que, para Vanja, sua vida começou na nação americana do sul:

Não tenho, claro, memórias da minha primeira infância em Albuquerque. Quando recuo no tempo, a sensação é de ter nascido no Rio de Janeiro. Mais 
especificamente, na praia de Copacabana - ali mesmo, sobre a areia, entre os pombos e o lixo que os frequentadores da praia deixavam para trás (LISBOA, 2010, p. 28).

A falta de memória de seus primeiros meses em terras norte-americanas faz com que Vanja seja uma estrangeira em território estadunidense. A partir disso, pode-se dizer que, no caso da protagonista, a narrativa não leva a cabo uma definição jurídica de estrangeiro, isto é, aquele nascido em outra nação, mas coloca em jogo uma visão da condição mais próxima daquela contemplada por Julia Kristeva em Estrangeiros para nós mesmos (1994). Para a pesquisadora, ser estrangeiro, para além de uma questão nacional, é uma condição existencial, na qual um indivíduo não se sente pertencente a lugar algum.

Vanja, dessa maneira, é estrangeira mesmo sendo estadunidense. Ela é o Outro devido a seu sotaque que se entrega na pronúncia errônea do fonema th, a suas opiniões julgadas como irrelevantes por seus colegas, e, como o trecho da ida à piscina nos mostra, à cor da sua pele:

Naquele mês de julho, o primeiro mês do meu Ano-Novo, Fernando me levou a uma piscina pública. As pessoas de pele clara se estatelavam nas espreguiçadeiras em busca de um bronzeado que custava a chegar, e que quando chegava tinha um certo avermelhado óbvio demais, avermelhado demais.

Assim como os outros latinos, e como os indianos, minha pele que já era marrom na origem ficava ainda mais marrom com uma hora de sol. Eu não sabia muito bem o que fazer com toda aquela melanina fácil, leviana, que se entregava ao sol como se fosse voluntária de algum rito sacrificial (LISBOA, 2010, p. 12).

A pele marrom, estereotípica do latino, que se entrega ao sol e difere da palidez dos estadunidenses brancos na piscina, causa um incômodo a Vanja por fisicamente a destacar como o Outro. O desconforto com sua pigmentação volta mais uma vez em uma visita ao dentista, na qual a protagonista, se comparando a uma fotografia da família do médico, afirma que "também era americana, segundo os meus papéis, mas em essência era um produto latino, estava na cara - e no resto do corpo - com aquele monte de melanina insistente na pele" (LISBOA, 2010, p. 40). Em outras palavras, a 
nacionalidade escrita no papel se torna descartável perante uma fisionomia que a rotula latino-americana.

A cena da piscina é também importante no que diz respeito à técnica narrativa usada por Lisboa para representar o sentimento de errância de Vanja: a justaposição entre Brasil e EUA. No romance, o estrangeirismo da narradora é trabalhado em uma série de contrastes entre os dois países em um movimento similar às ideias de Edward Said (2003) sobre como a consciência do migrante é contrapontística, suas experiências acontecendo "inevitavelmente contra o pano de fundo da memória dessas coisas em outro ambiente" (SAID, 2003, p. 59). Segundo Said, o exilado tem a consciência simultânea de duas ou mais culturas, a experiência do presente e a memória do lugar passado ocorrendo juntas como em um contraponto. Essa dinâmica seria responsável por uma visão de mundo original por parte desse deslocado. É dessa forma, numa constante volta ao passado em contraposição ao presente, que Vanja narra sobre seu primeiro ano nos EUA. Lisboa, portanto, constrói uma narrativa que conta a história de Vanja nos Estados Unidos contra um pano de fundo brasileiro, dando particular importância a uma característica identitária do país latino: suas águas.

Água, em particular, o mar, tem uma intricada relação com a identidade brasileira. Desde a Carta de Pero Vaz de Caminha, o território brasileiro, tem, de certo modo, sido definido em relação a suas águas. Ao falar dos rios, dos encontros ocorridos na praia e no mar, e encerrando o escrito com o que veio a se tornar uma das mais famosas afirmações da correspondência, "Águas são muitas; infindas. E em tal maneira é graciosa que, querendo-a aproveitar, dar-se-á nela tudo, por bem das águas que tem", Caminha cria uma narrativa em que um dos principais aspectos desta nova terra são as águas que aqui correm (1997, p. 51).

Anos mais tarde, na busca romântica pela construção de uma literatura nacional, José de Alencar retoma a tradição iniciada por Caminha ao abrir seu mito de fundação do Brasil, Iracema, no mar. A primeira cena do romance é, como sabido, a ida de Martim e Moacyr para a Europa após a morte de Iracema. Logo, o leitor começa a narrativa no Atlântico, olhando, junto a Martim, para uma "sombra fugitiva da terra", que seria o Brasil (ALENCAR, 2017, ebook). Dessa maneira, entramos no romance, e em terras brasileiras, através da água. O leitmotiv continua ao conhecermos Iracema, cujo nome escutamos no primeiro capítulo, mas cuja pessoa só aparece no segundo 
em uma estratégia narrativa de antecipação, enquanto ela banha "o corpo a sombra da oiticica, mais fresca do que o orvalho da noite" (ALENCAR, 2017, ebook). A situação marca o primeiro momento que Martim vê sua amada americana. A cena, é claro, alude às narrativas gregas em que herois espiam ninfas durante seus banhos, algo tornado tradicional na literatura ocidental, mas, para nosso propósito, cabe salientar como, novamente, a abundância de águas brasileiras é destacada.

Não deve causar estranheza, em vista disto, Lisboa eleger contrastar as identidades Brasil/EUA, ou, mais especificamente, Rio de Janeiro/Colorado, como modo de mostrar o sentimento de errância de Vanja através da hidrosfera de cada espaço. Isso posto, a narradora, como já vimos, sente que nasceu em Copacabana, a mais famosa praia brasileira, aos dois anos de idade, sua identidade profundamente definida pelas águas do país natal de sua mãe e incapaz de imaginar uma futura vida que não seja nesse espaço:

Quanto a mim, quando alguém me perguntava o que eu gostaria de ser quando crescesse só me passavam pela cabeça atividades que se desenrolassem numa faixa de areia, diante de alguma arrebentação. Vendedora de empada? (LISBOA, 2010, p. 34).

Ao voltar em sua memória, não lhe vem o sudoeste dos Estados Unidos, mas "um cheiro vago de maresia" e "o ruído das ondas fervendo na areia" (LISBOA, 2010, p.28). Seu lar é Copacabana:

Nasci portanto aos dois anos de idade na praia de Copacabana, e era sempre um verão, mas um verão irmão da água [...]

E lá adiante havia um horizonte sobre o qual eu não pensava. A faixa imaginária onde o céu e o mar se dividiam, líquido para um lado, não líquido para o outro. Uma espécie de abstrato concreto (LISBOA, 2010, p. 29).

O que existe depois do horizonte, um futuro para além da praia, é inconcebível. Seu mundo se resume ao ambiente praiano de Copacabana e não há vida fora de lá. Contudo, esse mundo se expande e ela, após a morte da mãe e na busca pelo pai, se encontra em Colorado, onde o verão e a água não são irmãos como no clima carioca, mas inimigos. Seu universo, agora, é seco: 
O ano começou em julho. O lugar era estranho. O suor corria por dentro, por trás da pele - eu suava e meu corpo continuava seco. Era como se o ar fosse duro, sólido, um ar de pedra. Eu bebia um copo d'água depois do outro até sentir a barriga estufada e pesada mas era sempre isso, o suor seco e o ar duro e o sol como um ferrão em cada raio. Não havia nenhuma brisa, nenhum hálito que viesse me aliviar um pouco entrando pelas frestas da blusa, levantando a barra da saia ou sacudindo meu cabelo com promessas de salvação (LISBOA, 2010, p. 11).

Lisboa escolhe abrir o romance com a secura do verão de Colorado, um clima árido inconcebível para quem, como Vanja, nasceu na umidade das praias cariocas e do qual não há onde encontrar alívio. Neste ambiente hostil, a pele da narradora resseca e sua garganta sangra, como se seu corpo rejeitasse esse novo espaço. Por isso, ao lançarmos um novo olhar para o episódio da piscina, podemos dizer que ele se caracteriza como uma busca por alívio numa volta a um ambiente aquático, mas a estratégia falha uma vez que o meio da piscina em Colorado continua não igualando a Copacabana:

Antes, em Copacabana, havia: biquínis minúsculos. Bundas de fora. Uma ou outra mulher passando água oxigenada nas pernas para alourar os pelos. Dependendo do ponto, muitas crianças. Dependendo do ponto, algumas prostitutas. Corpos musculosos, correndo sob o sol. Corpos flácidos correndo sob o sol. Sungas apertadas delineando o saco dos homens e revelando para que lado ficava o pênis. $[\ldots]$

Agora, em Lakewood, havia: biquínis e maiôs grandes em tecidos que às vezes formavam papadas na bunda. Homens de bermuda. Na beira da piscina, pessoas comendo hambúrguer e batata frita e bebendo cerveja refrigerante em copos king size de papel (LISBOA, 2010, p. 13-14).

O ambiente da piscina, que é, de certa forma, simulado, no sentido de ser criação humana ao contrário de uma praia, não corresponde (e não é capaz de suprir a ausência) à Copacabana. Leonardo Tonus, em sua tese sobre Samuel Rawet, argumenta que a memória do imigrante tem valor compensatório uma vez que o indivíduo deslocado carrega um sentimento de perda, que pode ser comparado ao luto e o presente é incapaz de reparar 
(TONUS apud CHIARELLI, 2007, p. 130). Dessa maneira, a ida à piscina para se aliviar da secura de Colorado e se sentir mais confortável resulta no aguçamento do sentimento de Vanja de estar fora do lugar dado que o passeio estimula uma volta à Copacabana de sua memória, onde sua cor não é estranha, as pessoas usam outros tipos de trajes de banho e não se come hambúrguer com batata frita à beira da água.

Colorado e sua secura se mantém ríspidos para Vanja porque aquele lugar não se concretiza, num primeiro momento, em um novo lar, mas é "um mero utilitário", pois estar "ali era estar em trânsito, e não tinhamos qualquer relevância para a vida um do outro" (LISBOA, 2010, p. 18). À vista disso, a oposição entre água/secura, Rio de Janeiro/Colorado, com a qual Lisboa constrói o romance serve para enfatizar como o passado na praia simboliza um lar afetivo para Vanja, enquanto a aridez do deserto é o abandono após a morte da mãe e a busca pelo pai. Como a própria Vanja narra:

Existe algo de intermediário nos desertos. Muitos viajantes disseram isso. É como se eles não fossem destinações, mas caminhos apenas. Grandes paisagens inóspitas onde você não se demora, que você apenas percorre entre um e outro ponto mais afável do mapa. E no entanto pessoas viviam ali. Pessoas vivem nos desertos e no ermos áridos e semiáridos do mundo. Nesses lugares entre parênteses (LISBOA, 2010, p. 147).

A vida de Vanja, então, ocupa este lugar que, em suas próprias palavras, está "entre parênteses". Classificação cabível, dado que, para ela, Colorado e seu deserto representa somente o período de desamparo entre a morte de sua mãe e o encontro com seu pai. Esse tem sido o principal ponto do romance analisado pela crítica literária. Stefania Chiarelli (2017), por exemplo, associa a oposição entre mar e deserto na narrativa à orfandade de Vanja; o primeiro se referindo ao passado materno e o último à vacância paternal. Dessa forma, a pesquisadora recorre a Olivier Mongin para apontar como o espaço exterior condiz com o vazio interior da personagem em relação à ausência do pai (CHIARELLI, 2017, p. 162). Luiza Puntar Muniz Barreto, por sua vez, recorrendo a Marc Augé, argumenta que o deserto na obra é um não-lugar e que "o aspecto mais expressivo da desterritorialização pela qual passa a personagem irá consistir, portanto, nessa oposição mar/deserto, que irá concretizar a dicotomia lugar/não lugar" (BARRETO, 2016, p. 138). 
Para Barreto, a relação entre Vanja e o lugar desértico, esse não-lugar, muda a partir do momento que ela para de se sentir abandonada na sua orfandade e forma laços afetivos com Fernando e Carlos. Concordamos com essa ideia em parte, mas ressaltaríamos que o espaço em si, como veremos, também se transforma à medida que Vanja muda.

\section{estrangeirismos e transformacooes}

Na conceituação de Marc Augé, o não-lugar é aquele espaço que não pode ser definido como relacional ou histórico e onde a identidade não é importante (AUGÉ, 1995, p. 79-80). Em outras palavras, são, hospitais, aeroportos, shoppings e outros locais onde indivíduos transitam no anonimato e com o qual não se estabelece uma relação íntima. Dessa forma, classificar o deserto de Colorado como um não-lugar com o qual Vanja não tem, em um primeiro momento, ligação afetiva, mas surge ao passo que suas relações com Fernando e Carlos se fortalecem, faz sentido. Entretanto, ao contrário de Barreto, não vemos que haja somente a conquista do deserto à medida que Vanja cria laços afetivos, mas que o próprio espaço desértico muda, simbolizando a transição de Colorado na vida da protagonista de não-lugar para lugar.

Ao considerarmos que as justaposições entre Brasil e Estados Unidos, entre mar/deserto, na obra são formas de mostrar o sentimento de estrangeirismo de Vanja, elas também se tornam passíveis de serem vistas como pertencentes a um processo de adaptação. Sendo assim, a pele ressecada que racha como reflexo de uma rejeição a seu novo espaço pode também indicar, como Vanja narra ao olhar seus dedos esbranquiçados, que ela está se tornando "progressivamente outra coisa, como se estivesse passando por uma lenta mutação" (LISBOA, 2010, p. 12).

As contraposições, portanto, vão desaparecendo ao longo da narrativa. As comparações feitas por Vanja, em especial, as diretas, nas quais ela fala do Colorado para logo em seguida falar do Brasil, como no caso da piscina, se concentram na primeira metade da obra, que aborda, justamente, os primeiros meses da personagem nos Estados Unidos. Ou seja, com o passar do tempo, as comparações vão diminuindo, indicando uma adaptação por parte da personagem a seu novo lar. 
Vanja, estadunidense de nascimento, tem um "passaporte americano (que me identificava, mas como qual eu ainda não me identificava)" (LISBOA, 2010, p. 14). Em um ensaio sobre o significado do passaporte na época contemporânea, Néstor Canclini afirma que

Como documento de identificación a la vez individual y nacional, el pasaporte está hecho para precisar el origen de los viajeros. Habilita para salir del lugar de nacimiento y a veces impedirlo. El pasaporte, combinación de acceso y encierro, sirve de metáfora a los hombres y mujeres de un tiempo multicultural [...] (CANCLINI, 2014, p. 2) $)^{2}$.

De acordo com Canclini, além de habilitar ou impedir o deslocamento de pessoas, sendo usado para decidir quem pode ultrapassar as fronteiras nacionais e quem deve ser barrado, o passaporte também tem o propósito de indicar de onde um indivíduo é oriundo - um aspecto, é sabido, importante para o primeiro uso citado. No caso de Vanja, o seu determina que sua origem é estadunidense. As implicações de poder envolvidas na personagem ter um documento que a identifica como sendo uma norte-americana nativa, logo uma cidadã beneficiada por todos seus direitos civis, serão abordadas mais à frente neste texto, mas, por agora, nos interessa apontar para como ela ainda não reconhece essa origem oficial que lhe é dada ao chegar nos Estados Unidos. Como já discutimos, Vanja, apesar de ter nascido em terras norte americanas, ocupa o lugar do Outro e se torna uma estrangeira ao voltar para seu país natal. Entretanto, agora com 22 anos e narrando sobre esse período de sua vida, ela indica que suas circunstâncias mudaram. $O$ advérbio usado pela personagem aponta seu reconhecimento que, aos treze anos, ela estava no início de uma trajetória durante a qual ela viria a ver aquele documento como correto ao caracterizá-la como uma estadunidense. O romance, portanto, não é só sobre o abandono maternal devido a uma morte e a busca de um pai biológico, mas também conta da transição identitária vivenciada por uma adolescente ao voltar para seu país de origem após viver por anos no de sua mãe. Sua própria idade no começo do processo, treze anos, o início da adolescência, é simbólica da transformação por vir.

2 Como documento de identificação ao mesmo tempo individual e nacional, o passaporte é feito para especificar a origem dos viajantes. Ele permite deixar o local de nascimento e, às vezes, impede esse movimento. O passaporte, uma combinação de acesso e confinamento, serve como uma metáfora para homens e mulheres de uma época multicultural (Tradução nossa). 
O processo já se inicia antes de Vanja sair do Brasil ao fazer suas malas, tendo que decidir o que é relevante levar e aquilo que precisa ser descartado. Ao considerar suas coisas, ela chega à conclusão de que "tudo que era importante deixava de ser quando confrontado com um olhar valente, com um olhar jogo do sério" (LISBOA, 2010, p. 14). Assim, livros, bichos de pelúcia, uma coleção de paralelepípedos (chamamos a atenção para como esses dois últimos são representativos de uma infância), entre outros itens, são rejeitados e, ao final, 11 anos de vida acabam por caber em duas malas pesando vinte quilos.

Com o passar do tempo, e da narrativa, nos Estados Unidos, Vanja vai se transformando, ou, se acostumando, pois, como Fernando lhe diz, "ninguém muda. A gente só vai se acostumando com as coisas. Vai se adaptando" (LISBOA, 2010, p. 62). Paralelamente à adaptação de Vanja ao Colorado, está a passagem do tempo e das estações. Ela chega ao deserto desacreditando o aviso de Fernando que o clima mudaria, mas percebe seu erro com a aproximação do fim do verão e a chegada do outono:

Mas contrariando todas as minhas expectativas e todos os indicativos no sentido de uma secura permanente, de um novo mundo cem por cento impune em sua rigidez desértica, começaram a aparecer chuvas, de vez em quando.

A primeira delas foi durante a noite. Acordei e estava tudo molhado, mas não durou, o sol confiscou de novo o que podia existir de água do chão [...]

A segunda chuva foi durante a tarde, miúda, e eu tive a impressão de que ela evaporava no meio do caminho, entre a nuvem e a terra, desistente. [...]

A terceira chuva foi um temporal que durou dezenove minutos, acompanhado de raios e trovões. Fiquei contemplando da janela o milagre fascinada (LISBOA, 2010, p. 38).

As chuvas, miúdas em um primeiro momento, se convertem em um temporal. A mudança é um aviso do outono que está por vir, o que, para Vanja, significa o início do ano letivo estadunidense e novas amizades como Aditi e Nick, jovens no seu ano na escola, e Carlos, seu vizinho salvadorenho. Significa, também, que ela passa a compartilhar de tradições culturais do país, como quando, tendo como exemplo, no outono, vai a um labirinto de milharal e trick-or-treating [a atividade de Doces ou Travessuras] no Dia das Bruxas. Nesta época, o tempo já virou e Vanja o encara "desconfiando 
daquela revolução de temperatura. Se era mesmo para valer" (LISBOA, 2010, p. 104). Em outras palavras, ela, como o tempo, está mudando e seu nível de conforto em seu novo espaço crescendo, contudo, ainda há uma incerteza presente e ela continua sendo uma estrangeira.

Mesmo perante esta desconfiança, no entanto, a alteração do tempo se concretiza e marcas da transformação identitária da narradora começam a aparecer, por exemplo, em sua linguagem:

Outra coisa que acontece quando você passa tempo demais fora de casa é que se depara com certas novidades no lugar novo através do idioma e daqui a pouco a língua que fala é uma estranha combinação de sintaxe em sua língua nativa mais um léxico de duas caras. Eu não dizia labirinto no milharal, dizia corn maze. Quando bati na porta de Carlos e o convidei para vir junto ele deu vivas, Qué bueno, corn maze, e foi correndo pedir à mãe. Como se não fosse deixar (LISBOA, 2010, p. 106).

É sabido que existe uma íntima relação entre língua e identidade, e o modo de falar de Vanja se torna mais híbrido à medida que ela passa a ocupar um lugar entre Brasil e Estados Unidos. "Labirinto no milharal", algo de pouco valor para a personagem uma que vez não é uma atividade costumeira no Rio de Janeiro, portanto, vira "corn maze" porque em Colorado ela frequenta esse espaço no outono assim como outros norte-americanos. O inglês, cuja aprendizagem ela resistia no Brasil, infiltra seu português, fazendo com que ela não mais possa falar como uma brasileira comum, mas que sua língua use o idioma português com marcas reveladoras de um estrangeirismo, assim como o morfema th em inglês denuncia que ela não é como qualquer estadunidense.

O ápice da relação entre sua mudança pessoal e o clima se encontra no inverno, quando, ao descer uma ladeira coberta de neve em um trenó, Vanja narra:

O ar voltava a ser duro, mas a essência dessa dureza era outra. Era preciso, de todo modo, acatar que ali as coisas raramente conheciam meios-termos. E de todo modo o que importava era que agora eu era um deles, sim, análoga, comparável a, semelhante. Numa confraria prosaica de corpos encasacados descendo encostas lisas, brancas, entre tombos reverentes e gritos de guerra. Eu também gritava, eu também levava tombos, eu também (LISBOA, 2010, p. 138). 
A dureza do ar retorna no inverno, mas não é a mesma rigidez que recepciona Vanja quando ela chega a Colorado. O ar duro do inverno não é o mesmo que o do verão, e a narradora agora não busca um lugar para escapar daquele espaço dilacerante, mas o adentra, camuflada por seus casacos entre os autóctones desse ambiente. Ela continua não sendo igual a eles, seu passado brasileiro nunca permitiria isso, mas ela agora é semelhante e, como a repetição de "também" ao final do trecho mostra, similarmente pertencente aos Estados Unidos. Voltando à questão da água, o Rio de Janeiro com seu mar é agora análogo a Lakewood coberto por neve. As águas que secaram e tornaram Colorado em deserto, sendo assim, voltam todo ano, em outra condição, o convertendo em um mar de neve.

Aqui conseguimos entender a opção de Lisboa por ambientar a história em Colorado e no Novo México. Primeiro, as quatro estações são distintas no Colorado e, ao decorrer da narrativa, transitamos por três delas. Iniciamos na aridez do verão, passamos pelo tempo mais ameno do outono e terminamos nas nevascas do inverno. Essa trajetória na qual o espaço muda, a água se fazendo cada vez mais presente, simboliza a trajetória identitária e emocional da protagonista. Dessa maneira, Colorado permite que Lisboa consiga criar a justaposição mar/deserto e transformar esse último em outro ambiente ao passo que a narradora se assimila a sua nova nação. Já o estado do Novo México e seu clima mais seco serve como lembrete da relação distante entre Vanja e seu pai biológico. É o tempo, descrito pela narradora ao chegar no estado em busca de seu pai como "um marrom uniforme e sedento", pois ainda "não tinha nevado em Santa Fé", que serve como presságio da decepção prenunciada (LISBOA, 2010, p. 155). Nessa viagem a uma Santa Fé onde não há neve, Vanja descobre a ida de seu pai biológico para África. A justaposição do clima dos dois espaços, portanto, enfatiza como os laços afetivos de Vanja estão em Colorado. Esse ponto é corroborado pelo reencontro entre pai e filha ocorrido fora de cena, reduzido a uma breve menção ao final do livro. Desse modo, no fechar da narrativa, Vanja não tem mais a praia de Copacabana, mas possui sua nova família nas planícies de Colorado cheias de neve e sua identidade agora é híbrida:

Depois que você passa tempo demais longe de casa, vira uma interseção entre dois conjuntos, como naqueles desenhos que fazemos na escola. Pertence aos dois, mas não pertence exatamente a nenhum deles.Você passa a ter uma memória sempre velha, sempre ultrapassada de casa. As pessoas estão escutando sem 
parar tal música no Brasil, toca na novela, toca no rádio. Seis meses depois você descobre a música por acaso, gosta dela, e a imensa popularidade prévia parece uma espécie de traição. É como se as pessoas estivessem trocando segredos, e você sempre se surpreendendo com notícias velhas. As pessoas do conjunto $A$ te consideram um ser meio à parte, porque você também pertence ao conjunto $B$. As pessoas do conjunto $B$ te olham meio de banda, porque você também pertence ao conjunto $A$. Você é algo híbrido e impuro. $E$ a interação dos conjuntos não é um lugar, é apenas uma interseção, onde duas coisas inteiramente distintas dão a impressão de se encontrar (LISBOA, 2010, p. 72).

Vanja, dessa forma, não é somente brasileira ou estadunidense, mas ocupa as duas posições. Nascida nos Estados Unidos, passa sua infância no Brasil e o início de sua juventude no país norte-americano. A personagem se encontra no meio do caminho entre o EUA do presente e o Brasil do passado, pois a versão atual deste último sempre chega a ela atrasada, desatualizada. Assim, ela também se torna uma estrangeira no país de sua infância, como, por exemplo, quando descobre ao visitar o Rio de Janeiro após sete anos fora que "a cidade era a mesma e não [...] era outra e não" (LISBOA, 2010, p. 214).

\section{a familia de imiorantes}

Abordar a questão da família no romance de Lisboa não é lugar novo. A crítica sobre a obra tem focado, com razão, em como, na narrativa, há uma relação direta entre a adaptação de Vanja aos Estados Unidos e seu relacionamento com Fernando e Carlos. Zilá Bernd e Tanira Rodrigues Soares (2016), por exemplo, apontam para como o livro se encaixa em uma atual vertente da literatura brasileira que tematiza a investigação de pais ou avós como pretexto para entender o próprio narrador e chegam à conclusão, com base em teorias de Joel Candau e Maurice Halbwachs, de que Fernando ocupa o espaço deixado por Suzana, mãe de Vanja, na vida da adolescente após sua morte. Já para Alessandra Dalva de Souza Pajolla, que investiga a questão da orfandade no artigo "Bastardos e órfãos contemporâneos" (2015), Vanja, Fernando e Carlos formam uma "comunidade afetiva". A autora, assim como Bernd e Soares, também vê o romance como pertencente a uma nova literatura do eu em que há uma busca pelos pais. 
Nossa leitura da família improvável formada no romance, contudo, segue por outro caminho. Na já mencionada entrevista de Adriana Lisboa, a autora afirma que "a experiência do imigrante legal, ilegal, do refugiado e de quem viaja por turismo são completamente distintas" (LISBOA, 2013, p. 215), e é através dessa ótica que desejamos analisar a "comunidade afetiva", seguindo a classificação de Pajolla, que se forma na narrativa, pois ela é composta por uma cidadã estadunidense (Vanja), um imigrante com documentos (Fernando) e um imigrante sem (Carlos).

Ao analisar a relação entre Vanja e seu passaporte na segunda parte deste artigo, assinalamos para como, no início de seu processo migratório, ela se sente estrangeira nos Estados Unidos, mas que, com o passar do tempo, ela começa a ver o rótulo de sua nacionalidade estadunidense no documento como correto. Entretanto, se considerarmos, retomando o texto de Edom Pires, que a obra se encontra na gradação entre a "consciência do exílio" e o "contato com a clandestinidade" em uma vertente de uma literatura atual sobre o deslocamento, temos que ponderar sobre como Vanja, apesar de se sentir estrangeira em um primeiro momento, se encontra em um lugar de privilégio em relação a Fernando e a Carlos.

No já mencionado ¿Qué representan hoy los pasaportes? [O que representam os passaportes hoje?], Canclini escreve que

Dos de las derivaciones grotescas, más antidemocráticas de esta política, son estas: a) consentir de la responsabilidad de los privilegiados ante los gastos públicos de sus Estados mediante la deriva de inversiones a paraísos fiscales e; b) la compra de nacionalidad y residencia europeas por quienes pueden pagar un millón de euros (CANCLINI, 2014, p. 4, itálico nosso) ${ }^{3}$.

Em um mundo no qual a nacionalidade virou uma comodidade, uma mercadoria à venda para aqueles que têm poder de compra, Vanja goza daquela que, provavelmente, tem maior valor: a estadunidense. Em seu texto, Canclini foca na Europa, mas ao lançarmos um olhar sobre os Estados Unidos, vemos que a cidadania estadunidense também é um bem a ser

3 Duas das derivações grotescas, mais antidemocráticas dessa política, são estas: a) consentir da responsabilidade dos privilegiados perante os gastos de seus Estados em relação ao desvio de investimentos a paraísos fiscais e; b) a compra da nacionalidade e residência europeias por quem possa pagar um milhão de euros (Tradução nossa, itálico nosso). 
vendido. Em uma notícia de 2017, por exemplo, o jornal Estado de São Paulo relatou que uma agência em Miami oferecia pacotes de viagens, que incluíam gastos com o parto e acompanhamento médico, para mulheres brasileiras grávidas e interessadas em terem seus filhos nos Estados Unidos e, assim, garantirem a cidadania a estes. Na época, casais chegavam a gastar até 100 mil reais na empreitada.

O deslocamento ao Estados Unidos para ter um filho é, dessa forma, um investimento. Se o passaporte serve para possibilitar e impedir um indivíduo de sair de seu lugar de nascimento, como Canclini nos diz, o número de muros para aqueles cuja nacionalidade é a estadunidense é menor que para as pessoas com o passaporte de qualquer nação latino-americana. Portanto, Vanja, norte-americana de nascença, pode não se sentir parte de sua nova comunidade no início, mas dispõe de todos direitos de uma cidadã do país e não está limitada à margem como Carlos. Aponta Edom Pires:

Sendo o imigrante aquele que sempre precisa validar sua presença por meio dos papeles, no livro de Adriana, o personagem Carlos, menino salvarenho, somatiza os medos da falta de registros. Sua presença em território americano será sempre a de quem se sente viajante mesmo estando em um lugar só, sempre a de quem precisa negar sua identidade primeira para afirmar uma nova identidade, que faz parte do sonho que impulsionou a viagem (PIRES, 2014, p. 397).

A história de Carlos e de sua família se constrói como pano de fundo da busca de Vanja pelo pai estadunidense, o contraste um lembrete de que os salvadorenhos não existem no mesmo nível de subalternidade que a adolescente. $O$ medo e o terror são constantes na vida daqueles que ocupam o espaço clandestino dos sin papeles e é assim que Carlos é roubado aos poucos de sua infância:

O bigode do pai dele falou, num espanhol espremido, que não era para o Carlos ficar dizendo por aí coisas como aquela. As pessoas denunciavam as outras (não, ele não se referia a nós - claro que não - nós éramos amigos - mas o Carlos tinha a língua solta). E num caso desses, no caso da denúncia, eles teriam que ir embora. IR. EMBORA. E o pior, teriam que deixar a Dolores para trás, porque agora ela estava na Flórida e a vida dela era outra coisa. E talvez nunca mais voltassem a ver a Dolores se por acaso tivessem que ir embora. E a mãe do Carlos começou a chorar 
baixinho e tapou o rosto com as mãos. Fernando pigarreou e olhou para a parede. Carlos foi imediatamente dominado pelo pânico, pediu desculpas e daquele dia em diante nunca mais pronunciou a palavra papeles.

Naquele momento, ele cresceu um pouco mais [...] (LISBOA, 2010, p. 140).

O menino vive em constante medo da deportação, seu deslocamento entre espaços comprometido por esse pânico. Ele não pode voltar a El Salvador para ver seus avós, não considera uma viagem a Flórida para ver sua irmã possível e, ao ser convidado por Vanja e Fernando para ir ao Novo México, o estado diretamente ao sul de Colorado, sua primeira dúvida é se é necessário ser documentado para fazer a viagem. Enquanto Vanja se movimenta entre Rio de Janeiro, Colorado, Novo México e, após encontrar o pai, Abidjan, na Costa do Marfim, de maneira tranquila, todo movimento de Carlos é marcado por um medo cotidiano.

Não é somente em comparação a Carlos que Vanja é privilegiada, entretanto, pois sua situação também é diferente da de Fernando:

Fernando já tinha dado tantas voltas depois de sair de casa que não lembrava mais qual o caminho. Claro: a casa já não estava mais lá, portanto o caminho não podia estar. E não é que a casa estivesse, agora, em toda parte - não, isso é para os cidadãos do mundo, para os que viajam por esporte. Para os que nunca se arrastaram sobre a lama congelada na China e nunca correram o risco de ser devorados pelos ursos no Alaska. Não é que a casa estivesse em toda parte: a casa não estava em parte alguma (LISBOA, 2010, p. 73).

Vanja pertence ao Brasil e aos Estados Unidos; ela existe em um entrelugar no qual sua identidade é simultaneamente brasileira e estadunidense. Carlos, como vimos, existe sempre como um viajante parado, sua falta de registro o tornando incapaz de pertencer aos EUA. Já Fernando, apesar de não estar em uma situação tão drástica como a do salvadorenho, também não pertence a lugar algum. Após sua experiência como guerrilheiro no Araguaia, ele não se vê mais no Brasil e, atualmente, como um migrante documentado nos EUA, não tem interesse em adquirir a cidadania. A diferença entre ele e Vanja fica clara ao final do livro quando a protagonista, após a morte de Fernando, começa a ocupar os espaços que esse deixou. Ela herda a casa, 
o carro e o trabalho na biblioteca municipal, "mas não como segurança" (LISBOA, 2010, p. 218). Fernando, imigrante com registro, era segurança de uma biblioteca e diarista para sobreviver, Vanja, cidadã norte-americana, não precisa fazer faxina e na biblioteca, supomos, exerce um cargo de maior privilégio.

Vanja, dessa forma, ocupa um lugar mais próximo ao "cidadão do mundo" que Fernando e Carlos. Seu passaporte estadunidense faz com que ela pertença a um universo sem fronteiras, seu salário em dólar a torna alguém com uma situação financeira superior a maioria do mundo. Já Fernando e Carlos se aproximam à ideia de cosmopolita pobre de Silviano Santiago.

"Uma nova e segunda forma de multiculturalismo", escreve Silviano Santiago sobre aquilo que ele vem a nomear cosmopolitismo do pobre, "pretende (1) dar conta do influxo de migrantes pobres, na maioria excamponeses, nas megalópoles pós-modernas, constituindo seus legítimos e clandestinos moradores" (SANTIAGO, 2008, p. 59). Não é mais somente aqueles, como Vanja, que têm as cidadanias corretas ou aqueles, como os pais dos bebês da reportagem do Estadão, que têm o dinheiro para comprar essa cidadania que atravessam as fronteiras nacionais. Hoje, o pobre também perpassa por essas barreiras na clandestinidade. Saskia Sassen (2011) toca nesta questão, argumentando que a mesma infraestrutura que possibilita a transição de capital, informação e bens entre fronteiras nacionais também é responsável, atualmente, pelo fluxo indesejado de homens, mulheres e crianças do Sul Global para o Norte (SASSEN, 2011, p. 58). Um dos argumentos principais da autora é que o processo de globalização criou cidades globais em que há, ao mesmo tempo, a demanda por profissionais de nível superior transnacionais e por mão de obra barata, fornecida pelas nações do Sul. Consequentemente, pode-se dizer que há o fluxo tanto de profissionais qualificados e de indivíduos de classe baixa do Sul para o Norte. Aquilo que Santiago chama de "cosmopolitismo do pobre" seria esse último grupo do qual Fernando e, sobretudo, Carlos fazem parte.

A família, portanto, não é composta por indivíduos iguais. Carlos vive com medo de ser deportado; Fernando, como repete ao longo da narrativa, acredita que basta se acostumar a seu novo país; e Vanja se assimila propriamente à sociedade estadunidense. Cada personagem, cada membro da "comunidade afetiva", dessa maneira, representa uma experiência imigrante diferente. 
Terminamos apontando para como a formação dos três personagens em uma família também toca na relação, no mínimo, problemática que o Brasil tem com o restante da América Latina. Como sabido, historicamente o Brasil tem tido maior interesse em forjar relações com a Europa e os Estados Unidos do que com o restante dos países da América do Sul, tendo uma dificuldade expressiva em se identificar como um povo latinoamericano. O fato de nossa herança cultural europeia ser portuguesa e não espanhola talvez seja um motivo para isso. Na narrativa, vemos essa diferença no interesse de Carlos em aprender português; em sua felicidade ao descobrir cognatos entre as duas línguas (ex.: amigo/amigo, trabajo/ trabalho, tiempo/tempo) e na sua decepção quando as palavras são diferentes (ex.: hijo/filho). Entretanto, também vemos o preconceito que imigrantes brasileiros têm com imigrantes hispânicos:

Talvez, uma outra hipótese, essa fosse a doença do imigrante latino-americano no primeiro mundo: o desespero de abraçar com toda a força o país rico e dizer quero um pedaço. Minha história não é só minha. É sua também. Por exemplo: de onde vem sua cocaína? A carne de seu churrasco? A madeira ilegal de sua estante? Sua história não é só sua. É minha também. Nosso American dream. Afinal, a América é um naco de terra que vai desde o oceano Ártico até o cabo Horn, não?

Se bem que os brasileiros sempre se colocaram de um modo bem claro nessa história: alto lá, não somos imigrantes hispânicos. Pode olhar para o meu rosto, a gente inclusive é bem diferente em termos de biotipo e não falamos espanhol, falamos português. POR. TU. GUÊS. (Na escola, eu tinha que preencher um papel com o meu grupo étnico. As opções eram: CAUCASIANO, HISPÂNICO, AMERICANO NATIVO, ASIÁTICO, AFRO-AMERICANO. Onde é que eu ficava nessa história?) (LISBOA, 2010, p. 71).

O brasileiro, portanto, está disposto a defender o discurso que somos todos americanos porque existe uma só América quando o argumento serve para nos aproximar dos Estados Unidos e do Canadá. Diferenças culturais e linguísticas causadas pelos diferentes processos de colonização são irrelevantes nesse caso. No entanto, temos pouco interesse em sermos classificados como membros de uma América excluidora dos angloamericanos. Mais à frente no romance, Lisboa novamente volta a abordar o preconceito sofrido por hispânicos entre brasileiros ao reproduzir uma página web em que brasileiros, no Brasil, discutem a migração Boliviana para 
o país (LISBOA, 2010, p. 103), e vemos que a posição de imigrantes brasileiros perante outros imigrantes latinos nos Estados Unidos é um reflexo de uma discriminação já existente no Brasil. Como Bernadete Beserra escreve, imigrantes brasileiros

raramente param para pensar sobre as razões pelas quais, nos Estados Unidos, a categoria latino tem um significado tão diferente daquele que tem no Brasil. Eles geralmente optam pelo caminho do racismo dominante, não enfrentando a própria latinidade, porque eles também acreditam que o Brasil, e consequentemente os brasileiros, são também um pouquinho superiores aos outros latinos (BESERRA, 2000, p. 7).

O texto de Beserra aborda a relação entre brasileiros habitantes de Los Angeles e os hispânicos que também estão na região. A pesquisadora chega à conclusão de que apesar de imigrantes brasileiros nos Estados Unidos reproduzirem o discurso racista em relação a outros latinos no país, alguns percebem suas limitações de ascensão socioeconômica por também serem vistos como latinos e se aliam aos hispânicos na luta por direitos (BESERRA, 2000, p. 18-19). Vanja, Fernando e Carlos, portanto, não formam uma "comunidade afetiva" qualquer, mas uma cuja base é a experiência do imigrante latino-americano nos EUA, mesmo que essas três experiências sejam distintas.

\section{consideracões finais}

Pelo dito aqui, é evidente que Azul corvo faz parte de um viés da literatura brasileira contemporânea sobre a questão do deslocamento. O percurso proposto neste artigo foi uma tentativa de compreender como Adriana Lisboa, ao escrever o romance, lança um olhar para a atual conjuntura global em que o Brasil, junto com outros países da América Latina, exporta corpos para os países desenvolvidos que têm os Estados Unidos em seu cerne. Dessa forma, apesar de o romance pertencer a um viés literário contemporâneo que aborda a orfandade, ele vai além da história de uma adolescente em busca de seu pai.

Pensando na colocação de Edom Pires sobre uma literatura entre a "consciência do exílio" e o "contato com a clandestinidade", Lisboa cria um 
universo ficcional em que o leitor se depara com diferentes experiências migrantes possíveis no mundo atual. Logo, considerando uma tradição literária brasileira na qual o espaço narrativo tem sido o Brasil e o estrangeiro aquele que vem de fora, Lisboa trata de uma nova possibilidade que tem surgido para autores que escrevem a temática da migração: o brasileiro em terras estrangeiras. Isso se dá justamente pela escrita da autora, assim como muitos de seus contemporâneos, ser caracterizada por uma desnacionalização do espaço. Cada vez mais na literatura brasileira atual há um interesse em olhar para além das fronteiras nacionais, e a ficção de Lisboa reflete esse desejo. Ao imigrante sem registro que vive na clandestinidade, ao migrante legal que não vê nenhum país como seu lar, ao indivíduo cuja identidade está dividida entre duas nações, em Azul corvo é dado o espaço necessário para refletir sobre a errância em um mundo globalizado. Desse modo, a vivência daquele fora do lugar toma o primeiro plano na narrativa, levantando questões e discussões sobre como é ser estrangeiro hoje.

\section{referências}

ALENCAR, José de. Iracema. 2 ed. Brasília: Câmara dos Deputados, Edições Câmara, 2017. ebook.

AUGÉ, Marc. Non-places: introduction to an anthropology of supermodernity. Tradução de John Howe. London; New York: Verso, 1995.

BARRETO, Luiza Puntar Muniz. Deslocamentos espaciais e identitárioafetivos em Azul-Corvo. Revell. v. 2, ano 7, n. 13, ago. 2019, p. 131-147. Disponível em: <https://periodicosonline.vems.br/index.php/REV/article/ view/1142>. Acesso em: 2 ago. 2018.

BERND, Zilá; SOARES, Tanira Rodrigues. Modos de transmissão intergeracional em romances da literatura brasileira atual. Alea. v. 18/3. set./ dez. 2016. p. 405-421. Disponível em: <https://revistas.ufrj.br/index.php/ alea/article/view/22616>. Acesso em: 4 set. 2018.

BESERRA, Bernadete. A integração brasileira no mundo latino de Los Angeles. In: ENCONTRO ANUAL DA ANPOCS, 20., 23-27 Oct. 2000, Petrópolis. São Paulo: ANPOCS, 2000. Conference Presentation. Disponível em: <https:/l bit.ly/2zUSqBT>. Acesso: 15 jan. 2019. 
BASSETTE, Fernanda. Brasileiras vão aos EUA para ter bebê e garantir cidadania americana aos filhos. Estado de São Paulo. São Paulo, out. 2017.

CANCLINI, Nestor Garcia. ¿Qué representan hoy los pasaportes?. Revista Otra parte. Buenos Aires: Siglo XXI, p. 1-4, maio 2014.

CHIARELLI, Stefania. Vidas em trânsito: as ficções de Samuel Rawet e Milton Hatoum. São Paulo: Annablume, 2007.

CHIARELLI, Stefania. Forasteiras - Adriana Lisboa e Paloma Vidal, percursos itinerantes na ficção contemporânea. In: DAFLON, Claudete; GARBERO, Maria Fernanda; SANTOS, Matildes Demétrio dos. Agentes do contemporâneo. Niterói: EDUFF, 2017. p. 159-170.

CORTESÃO, J. Carta de Pero Vaz de Caminha a El-Rei D. Manuel sobre o Achamento do Brasil. Lisboa: Parque Expo 98, 1997.

KRISTEVA, Julia. Estrangeiros para nós mesmos. Tradução de Maria Carlota Carvalho Gomes. Rio de Janeiro: Rocco, 1994.

LISBOA, Adriana. Azul corvo. Rio de Janeiro: Rocco, 2010.

LISBOA, Adriana. Entrevista com Adriana Lisboa. [Entrevista concedida a Amanda Mendes Casal]. Belas Infiéis. v. 2, n. 1, p. 213-220. set. 2013. Disponível em: <https://periodicos.unb.br/index.php/belasinfieis/article/view/11231>. Acesso em: 6 jun. 2018.

PAJOLLA, Alessandra Dalva de Souza. Bastardos e órfãos contemporâneos: a arqueologia da infância nos romances de filiação. Estudos de Literatura Brasileira Contemporânea. n. 46, p. 105-116, jul/dez. 2015. Disponível em: $<$ https://periodicos.unb.br/index.php/estudos/article/view/10037>. Acesso em: 8 jul. 2019.

PIRES, Maria Isabel Edom. Em viagem: sobre outras paisagens e movimentos no romance contemporâneo. Estudos De Literatura Brasileira Contemporânea, n. 44, p. 389-403. 2014. Disponível em: <https://periodicos.unb.br/index. php/estudos/article/view/g9g9>. Acesso em: 15 jun. 2019.

SAID, Edward. Reflexões sobre o exílio e outros ensaios. Tradução de Pedro Maia Soares. São Paulo: Companhia das Letras, 2003. 
SANTIAGO, Silviano. O cosmopolitismo do pobre. In: O cosmopolitismo do pobre: crítica literária e crítica cultural. Belo Horizonte: Editora UFMG, 2008. p. 45-63.

SANTOS, Claudete Daflon dos. A viagem e a escrita: uma reflexão sobre a importância da viagem na formação e produção intelectual de escritoresviajantes brasileiros. 2002. Tese (Doutorado em Letras) - Departamento de Letras, Pontifícia Universidade Católica do Rio de Janeiro. Rio de Janeiro, 2002.

SASSEN, Saskia. Global Migration and Economic Need. In: SASSEN, Saskia. Citizenship, Borders, and Human Needs. Philadelphia: University of Pennsylvania Press, 2011. p. 56-91.

Artigo recebido em: 02/02/2020 Artigo aceito em: 27/05/2020 